\title{
PETROFÁBRICA DE MIGMATITOS DOS ARREDORES DE AMPARO, SP
}

\author{
EBERHARD WERNICK* e ANTÔNIO GARLOS ARTUR**
}

\begin{abstract}
This paper presents the results of a microtectonic study of migmatitic rocks from the Amparo Group (State of Såo Paulo, Brazil) involving minerals of melanosome (biotite) and leucosome (quartz). The authors concluded that melanosome reveals structures grading from $S$-tectonites to $L$-tectonites $(S-L$ system) respectively modified by one or more co-planar linear components and by co-axial planar components. Leucosome exhibits structures mainly of $L$-tectonite grading to isotropic structural patterns. Such differential behavior has been interpreted as a result of migmatization processes, in which the remobilized Si-Al metatect tends to be dislocated to places of lower pression with increasing structural degree of freedom. However microtectonic information is clear enough to permit correlation of the metatectic material with the high intensity metamorphic phase. The authors also analyse the structural characterists of the rocks as a whole and conclude that they show apparently only one global tectogenic event which, however, do not exclude the possibility of sucessive homoaxial superposed deformation or the vanishing of prior deformation by later tectonic overprinting.
\end{abstract}

INTRODUÇÃO Um dos problemas ligados ao estudo de fenômenos de migmatização é representado pelas relações entre a deformação da rocha, a mobilização de material de caráter granitóide (granítico, adamelítico, granodiorítico, tonalítico) e as características estruturais do metatecto. Metatectitos flebíticos do tipo estromatítico, diadisítico e ptigmático (Bonorino, 1970), denotando elevada plasticidade, sugerem que a produção do mobilizado (metatecto) seja muito mais um produto de "fusão" parcial local (diatexia) de rochas preexistentes que uma segregação metamórfica ou ação metassomática sob forte controle estrutural, como sugerem certos tipos de migmatitos oftalmíticos e embrechíticos. No presente trabalho os autores apresentam os resultados de exame microtectônico realizado em migmatitos do Grupo Amparo analisando, comparativamente, a petrofábrica do leucossoma e melanossoma de estromatitos.

Geologia regional $\mathrm{O}$ complexo metamórfico-granítico, situado na área compreendida entre Campinas, Itatiba, Bragança Paulista, Socorro, Lindóia e Águas de Lindóia (Fig. 1), foi estudado principalmente por Franco e Coutinho (1957) e Wernick (1967, 1972a, b, c). O complexo tem sido denominado informalmente de "Grupo Amparo" (Ebert, 1968, 1971). Constitui, na região, o substrato da borda oriental da Bacia do Paraná. Tectonicamente, a área em questão situa-se no Bloco Jundiaí (Hasui et al., 1969), limitado ao sul pelas falhas de Jundiuvira e Itu, e ao norte pela falha de Jacutinga, ambas de caráter transcorrente e com sinais de reativação em regime de falha normal. O bloco tectônico ao norte da falha de Jacutinga é designado bloco Pinhal, sendo constituído essencialmente por migmatitos altamente evoluídos e rochas graníticas, recebendo este complexo a designação informal de "Grupo Pinhal" (Wernick e Penalva, 1973), sem que, entretanto, as suas relações com outras unidades estejam suficientemente esclarecidas. Já o bloco ao sul é conhecido como Bloco São Roque (Hasui et al., 1969), sendo constituído por rochas epimetamórficas do Grupo São Roque (ou Açungui).

* Departamento de Geologia e Mineralogia, Faculdade de Filosofia, Ciências e Letras de Rio Claro. Gaixa. Postal 178, 13500, Rio Claro, São Paulo, Brasil

**Bolsista do Conselho Nacional de Pesquisas 


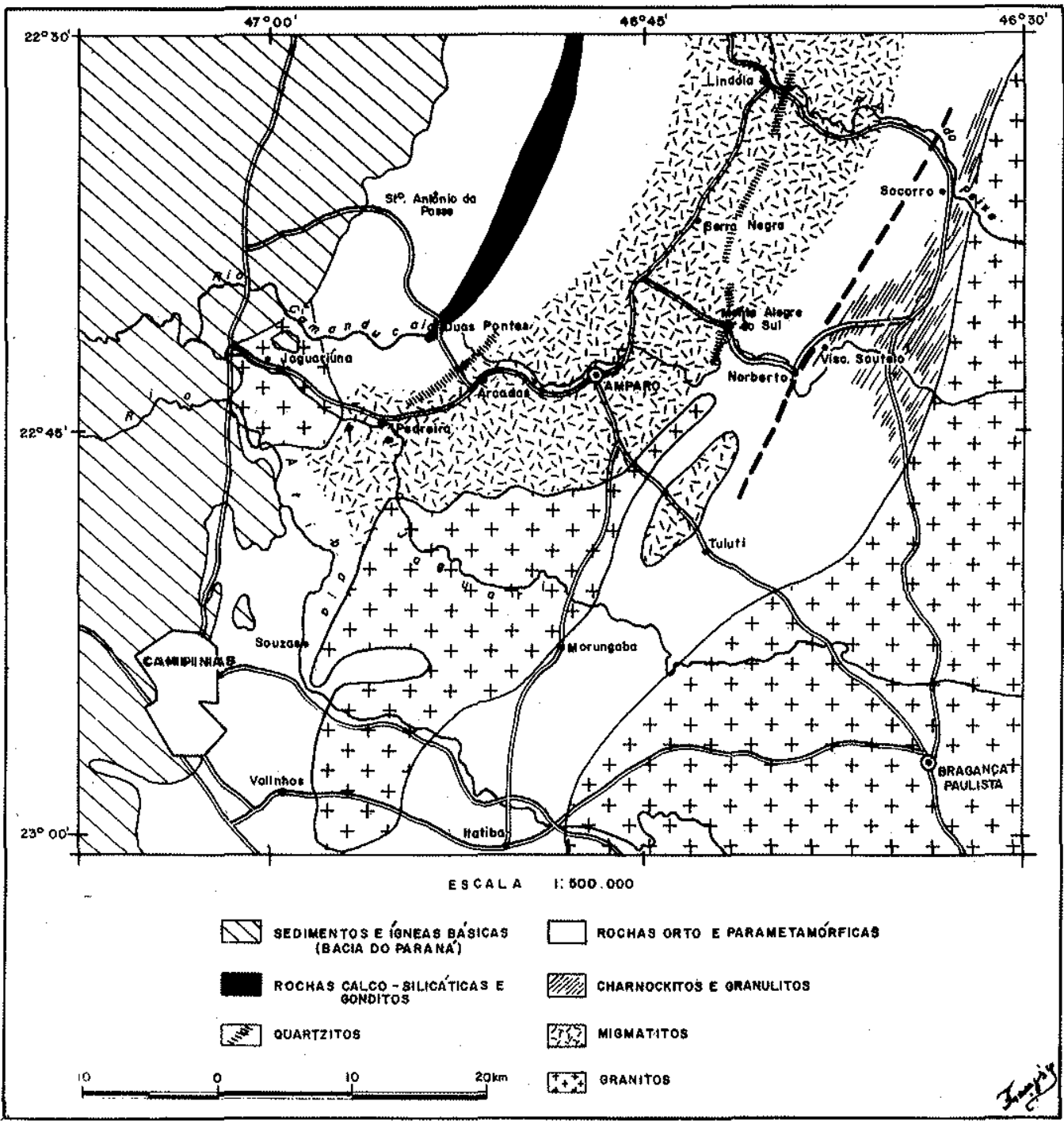

Figura 1 - Mapa geológico simplificado da regiåo de Amparo

O "Grupo Amparo" é constituído por gnaisses e migmatitos, ricos em intercalações anfibolíticas, associados a quantidades menores de rochas calco-silicatadas, biotita xistos, quartzitos, gonditos, granulitos e charnockitos. Rochas graníticas, equigranulares e porfiroblásticas constituem tanto corpos maiores (maciços de Jaguariúna, Morungaba, Socorro) quanto corpos menores (Campinas, I tatiba, Arcadas).

A direção estrutural regional é em torno de $\mathrm{N} 40 \mathrm{E}$, com flutuações locais. O padrão de dobramento é de dobras abertas até isoclinais com os eixos ostentando direção preferencial NE-SW com inclinação predominante de $20^{\circ}$ tanto para NE quanto SW. A foliação, gnaissificação e xistosidade têm mergulhos elevados, geralmente superiores a $45^{\circ}$.

Determinações geocronológicas pelo método K :Ar (Cordani e Bittencourt, 1967) em rochas metamórficas (anfibolitos, biotita xistos) e graníticas (granitos, granitos pórfiros) do "Grupo Amparo" revelaram idades absolutas do resfriamento regional e atividades 
magmáticas compatíveis com o Ciclo Brasiliano. Idades $\mathrm{K}$ : Ar disponíveis para o Grupo São Roque (Cordani e Bittencourt, 1967; Hasui e Hama, 1972) e do "Grupo Pinnal" na área de Pinhal (Ebert e Brochini, 1968) e de K:Ar e Rb:Sr nos arredores de São José do Rio Pardo (Oliveira, 1972) são compatíveis com os obtidos para o "Grupo Amparo", se bem que os dados ainda sejam insuficientes. Isso năo exclui, entretanto, a ocorrência, no Bloco Jundiaí, de rochas mais antigas, como revelou uma determinação $\mathrm{K}$ : Ar em anfibolito (Hasui e Hama, 1972).

Material e métodos $\mathrm{O}$ material utilizado no presente trabalho foi coletado na $\mathrm{Pe}-$ dreira Granito, $1 \mathrm{~km}$ a oeste da cidade de Amparo, junto à SP-95. Trata-se de um migmatito metatectico flebítico do tipo estromatítico, diadisítico e ptigmático (Bonorino, 1970). Foram coletadas tanto amostras de caráter mais regular (Fotos 1, 2 e 3, amostra A-G) quanto de material granítico de ocorrência discordante (Foto 4, amostra H). Dada a natureza do presente trabalho, não houve necessidade de coleta de material orientado. $\mathrm{O}$ material, após laminação perpendicular ao elemento estrutural de referência mais evidente $(S$ ou $B)$, foi examinado à platina universal, determinando-se em cada lâmina a posição do eixo óptico dos grãos de quartzo do leucossoma metatectico e o plano $\{001\}$ nas biotitas do melanossoma. Para facilitar a comparação entre os diversos diagramas, os elementos

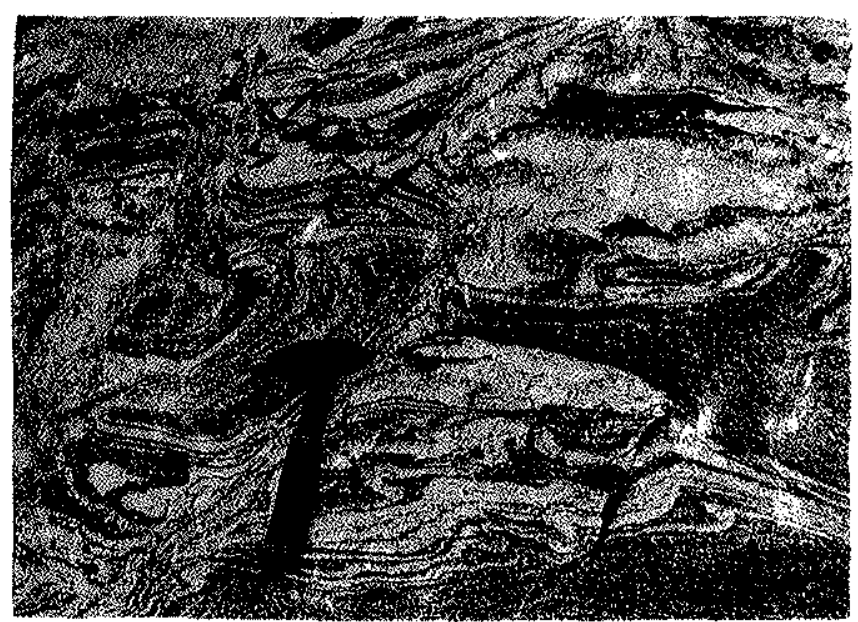

Foto 1 - Migmatito Amparo. Localização das amostras A, B e C

Foto 2 - Migmatito Amparo. Localização das amostras D e E.

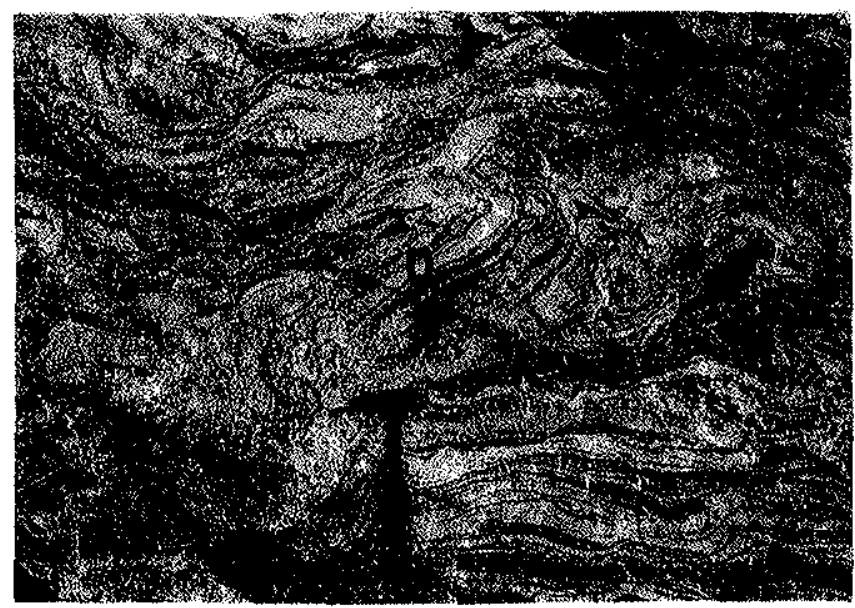




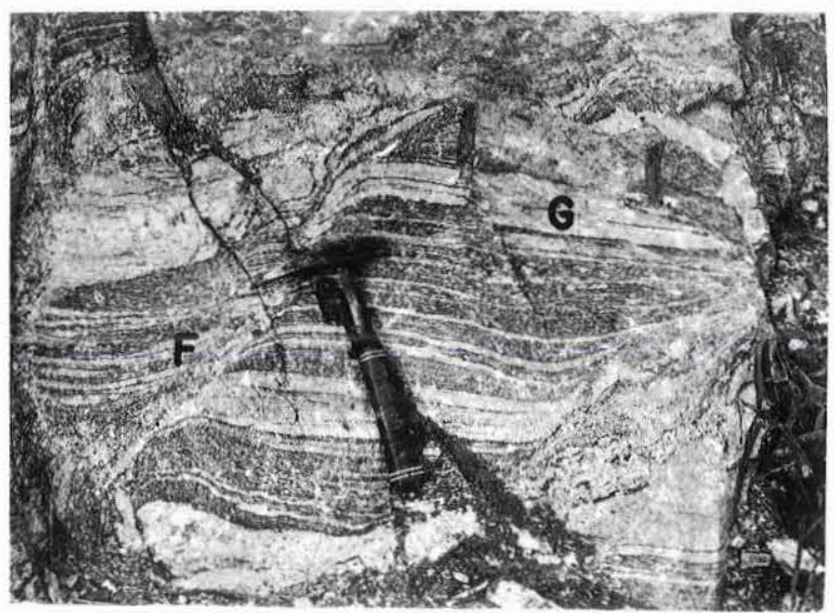

Foto 3 - Migmatito Amparo. Localização das amostras F e G

Foto 4 - Migmatito Amparo. Localização da amostra $\mathrm{H}$

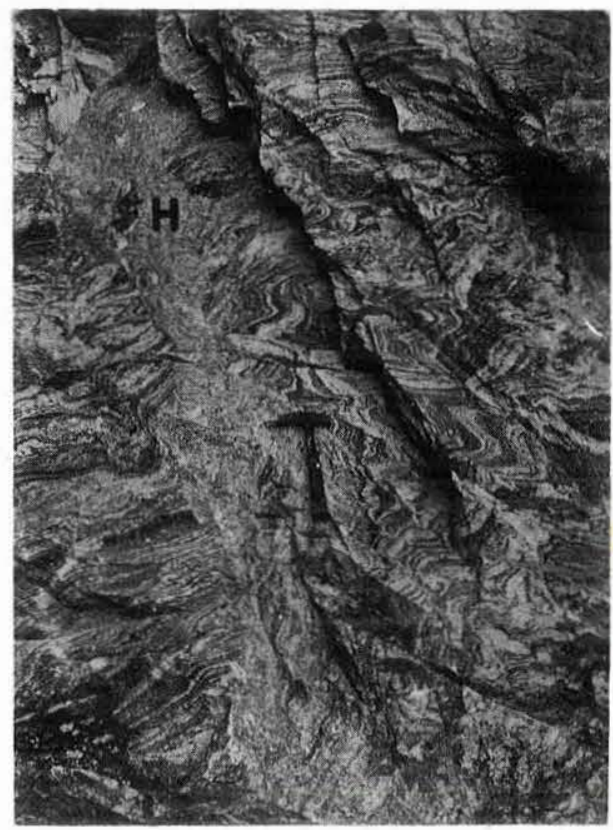

estruturais macroscópicos de referência foram colocados em posição vertical. $\mathrm{Q}$ número mínimo de determinações por lâmina foi de duzentos indivíduos em cada espécie mineral considerada. Os dados obtidos foram projetados em diagrama Schmidt-Lambert (no caso das biotitas o pólo do plano $\{001\})$ e quantificados com rede de integração LAMPRO 103 e 203 (Braun, 1969). Os diagramas obtidos estão representados nas Figs. 2 a 15. Em cada figura está assinalado o número de medidas realizadas.

RESULTADOS E DIScUSSÃo BIOTITA Os diagramas obtidos em pólos $\{001\}$ de biotita evidenciam que os migmatitos do "Grupo Amparo" mostram uma passagem estrutural completa entre tectonitos do tipo $\mathbf{S}$ (tectonitos planares) e tectonitos do tipo $\mathbf{B}$ (tectonitos lineares), correspondendo os casos extremos, respectivamente, às amostras $A$ (Fig. 2) e $F$ (Fig. 7). O exame das Figs. 5, 6 e 7 evidencia que se trata de tectonitos $\mathbf{B}$ de cisalhamento com simetria rômbica. A passagem estrutural completa entre tectonitos $\mathbf{S}$ 
Figura 2 - Estromatito, melanossoma, biotita. Amostra A

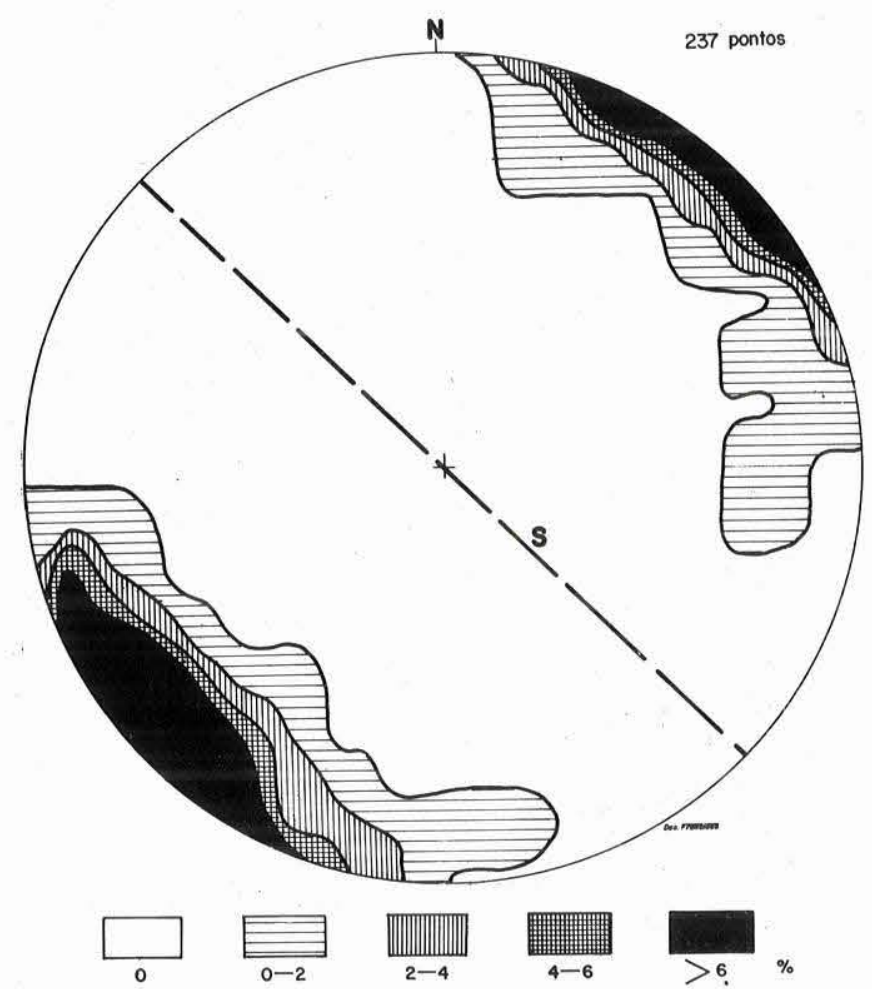

Figura 3 - Estromatito, melanossoma, biotita. Amostra B

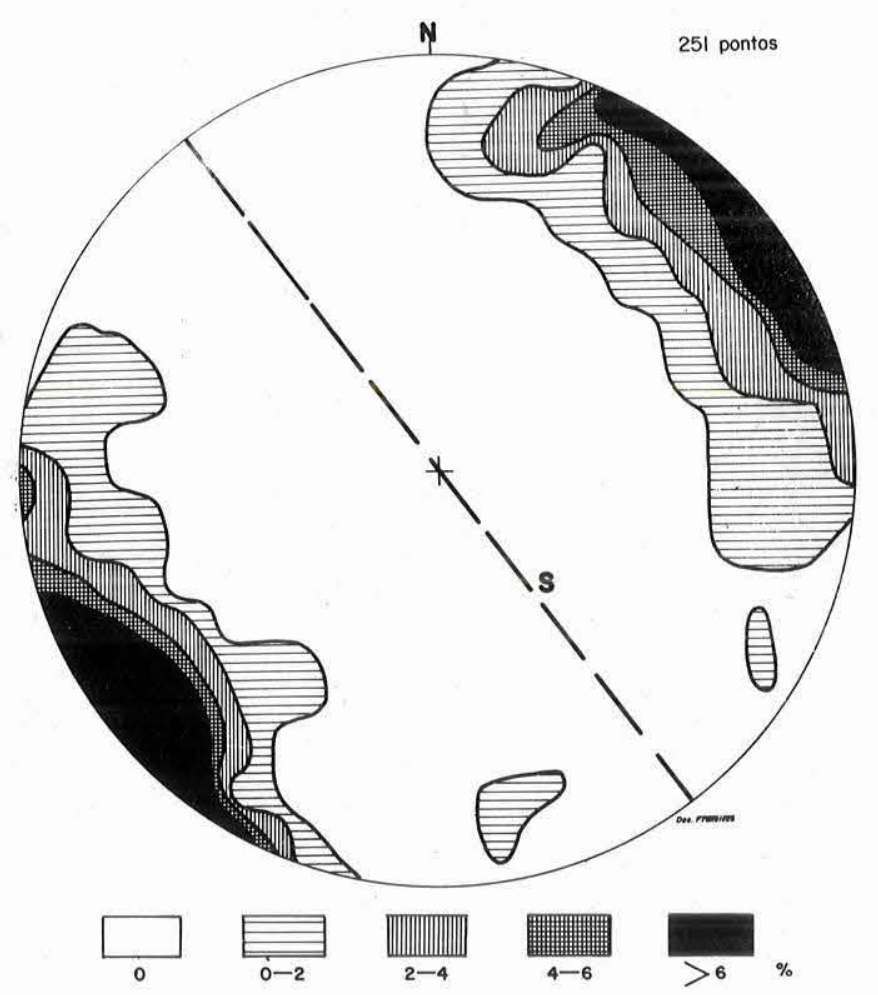




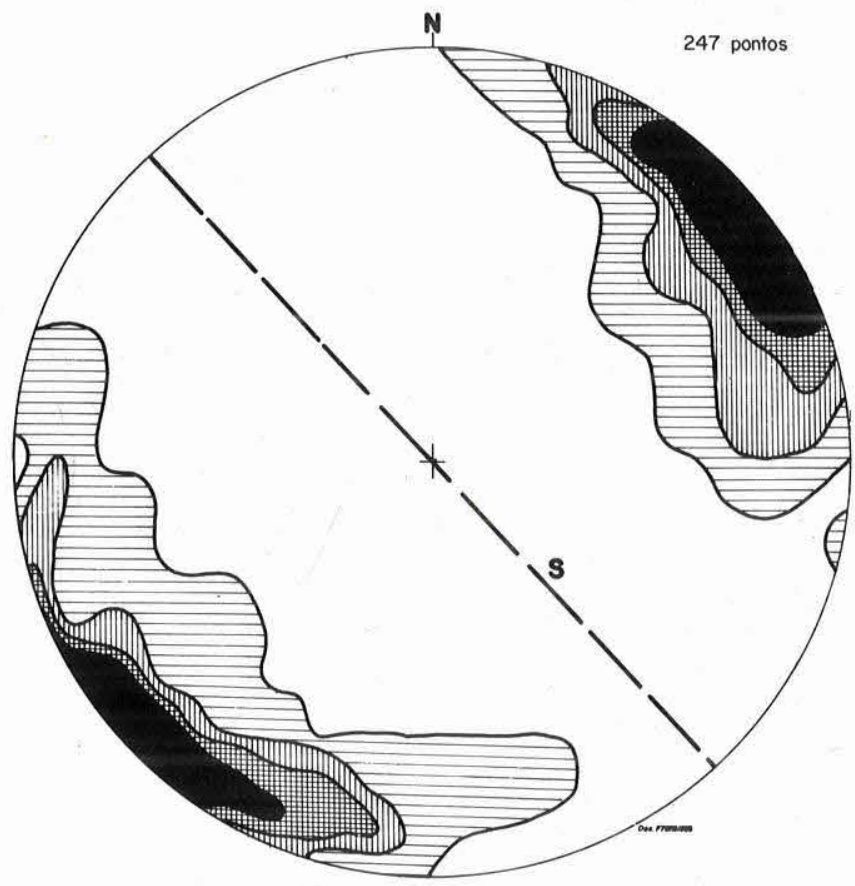

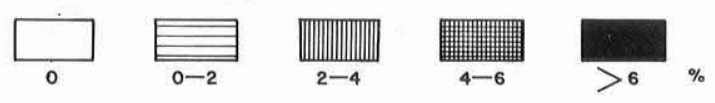

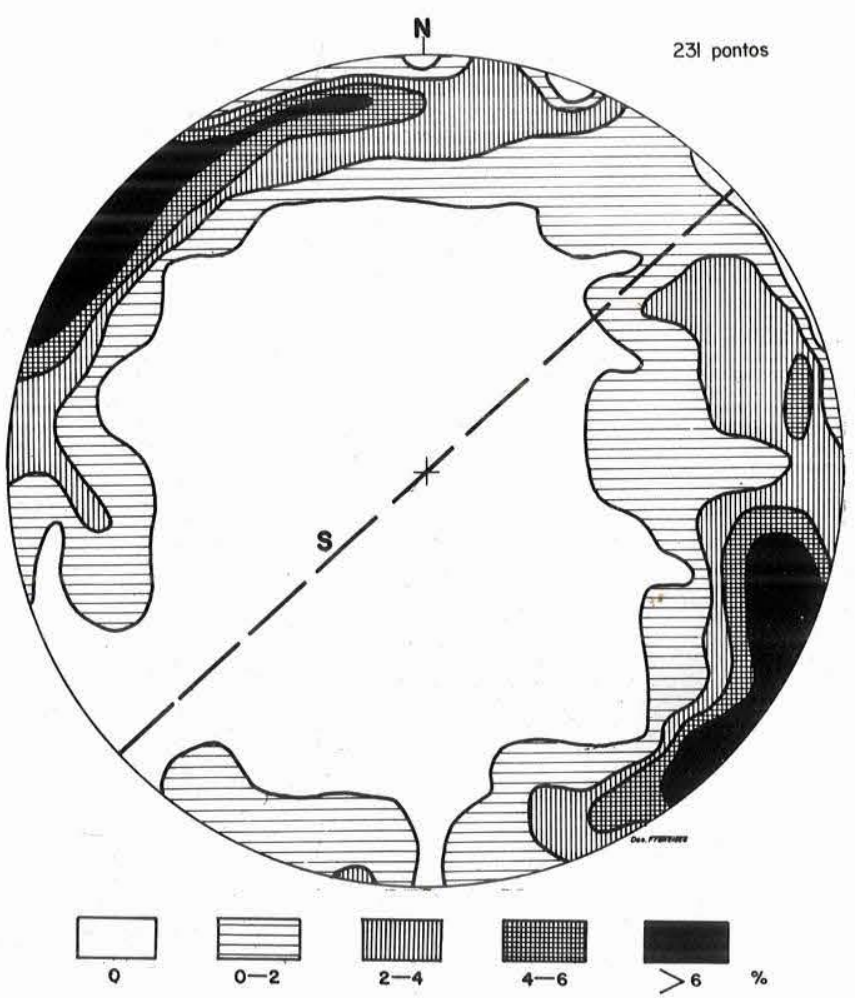

Figura 4-Estromatito, melanossoma, biotita. Amostra C
Figura 5 - Estromatito, melanossoma, biotita. Amostra, D 
Figura 6-Estromatito, melanossoma, biotita. Amostra E

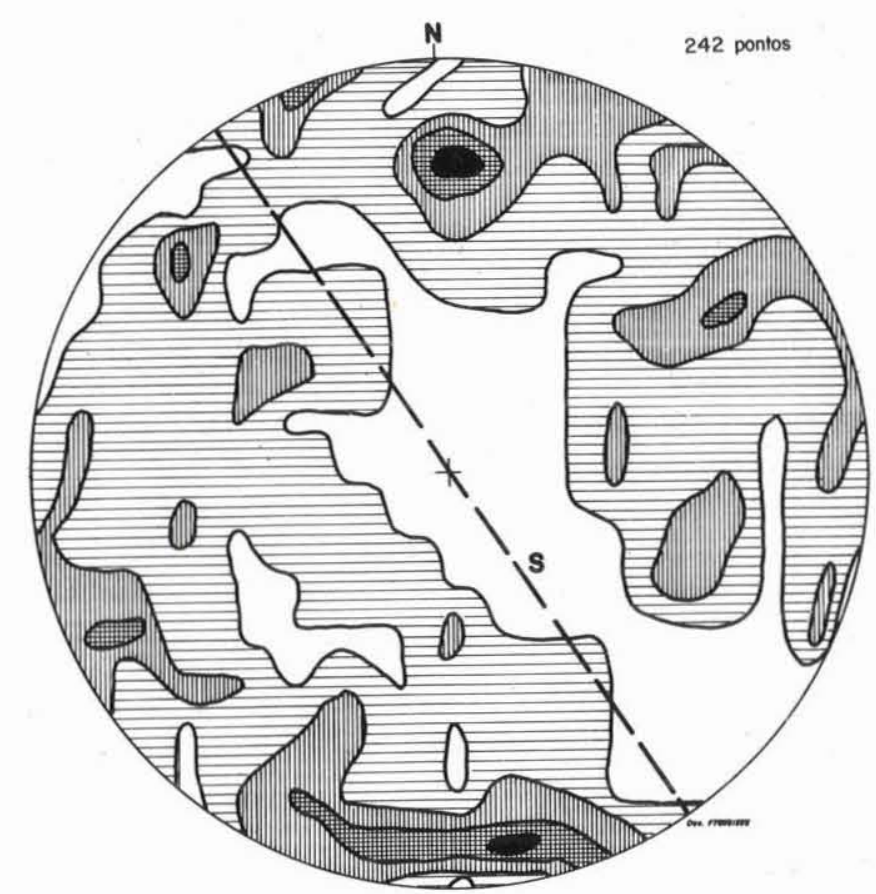

Figura 7 - Estromatito, melanossoma, biotita. Amostra F
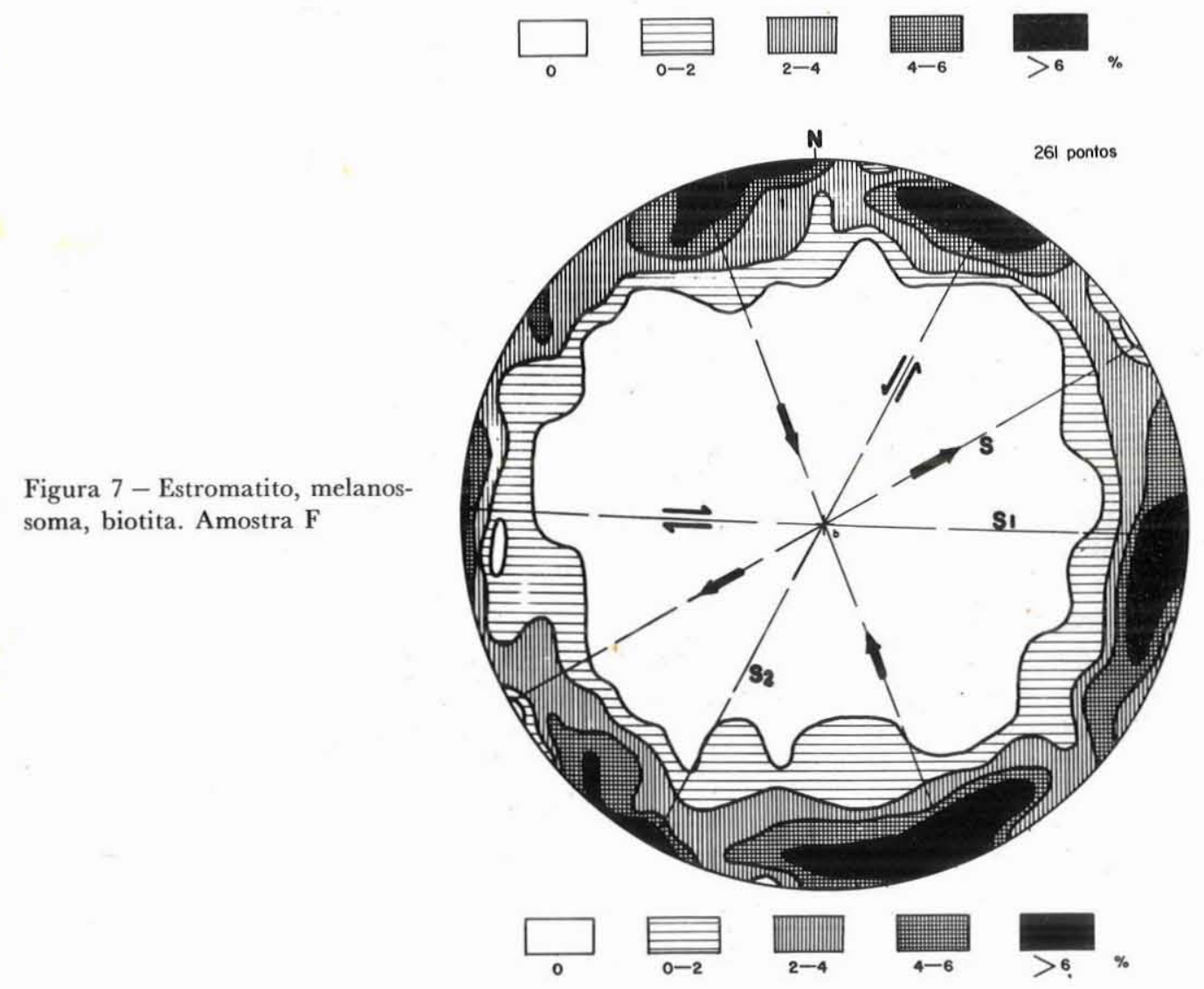
e B caracteriza para o paleossoma um sistema L-S típico (Flinn, 1965, em cuja nomenclatura os tectonitos B são designados por tectonitos L), que é considerado o resultado de deformações homogêneas. As variações rápidas nas características petrofábricas de amostras provenientes de localidades próximas indicam:

a) que a deformação dos migmatitos Amparo sofre rápidas flutuações quanto aos esforços relativos com $\mathrm{Z}=\mathrm{Y} \neq \mathrm{X}$ (tectonito $\mathrm{S}$ ) via $\mathrm{X} \neq \mathrm{Y} \neq \mathrm{Z}$ (tectonitos $\mathbf{L}-\mathbf{S}$ ) até $\mathrm{X}=\mathrm{Y} \neq \mathrm{Z}$ (tectonito $\mathbf{L})$.

b) que a área de predominância de cada tipo de deformação é relativamente pequena. Isso está de acordo com as idéias de Flinn (1965) de que deformações do tipo $\mathbf{S}$ e $\mathbf{L}$ não devem ser consideradas feições independentes, como sugerem suas respectivas simetrias, e sim casos extremos de um mesmo sistema de deformações, no qual o tectonito $\mathbf{S}$ ocupa a posição de liberdade mínima e o tectonito $\mathbf{L}$, a de liberdade máxima.

c) a ocorrência tanto de estruturas lineares modificadas por um ou mais componentes planares co-axiais (Figs. 5, 6 e 7) quanto a ocorrência de estruturas planares modificadas por componentes lineares co-planares (Figs. 2, 3 e 4).

QUARTZO Os leitos de leucossoma que se alternam com os de melanossoma nos migmatitos estromatíticos ostentam, via de regra, petrofábrica com maior grau de liberdade que a do correspondente melanossoma associado. Assim, enquanto na amostra $A$ a biotita do melanossoma constitui um tectonito $\mathbf{S}$ (Fig. 2), a petrofábrica do neossoma associado exibe feições tendendo a um tectonito $\mathbf{L}$ (Fig. 8). Já na amostra $B$ a discrepância é maior. A biotita configura um tectonito S-L (Fig. 3) enquanto o quartzo sugere forte tendência para isotropia estrutural, com a ocorrência de máximos de concentração de distribuição caótica (Fig. 9). Relação semelhante ocorre na amostra $C$ com a biotita constituindo um tectonito S-L (Fig. 4) e o quartzo um tectonito $\mathbf{L}$ modificado por elementos planares co-axiais (Fig. 10). A petrofábrica do leucossoma e melanossoma da amostra $D$ (Figs. 5 e 11) são equivalentes, o mesmo ocorrendo com as amostras $E$ (Figs. 6 e 12) e $F$ (Figs. 7 e 13). A amostra $G$ (Fig. 14), proveniente de um espesso banco leucocrático e sugerindo ausência de remobilização, ostenta padrão estrutural de tectonito $\mathbf{S}$ cisalhado, semelhante à amostra $F$ (Figs. 7 e 13). Já a amostra $H$ (Fig. 15), a despeito do caráter discordante do material granítico remobilizado, ainda ostenta petrofábrica de um tectonito $\mathbf{L}$ modificado por componentes planares co-axiais. A análise dos dados obtidos indica que:

a) o grau de liberdade da petrofábrica do leucossoma é equivalente ou maior que o do correspondente melanossoma. Essa diferença deve ser procurada na mobilidade diferencial entre minerais siálicos e máficos durante o processo da migmatização. Como conseqüência, o melanossoma guarda com maior precisão as feições do estágio pré-mobilização, enquanto o metatecto, cuja tendência é de alojar-se nos locais de menor pressão, tende a exibir uma petrofábrica caracterizada por maior grau de liberdade (tectonito $\mathbf{L}$ e isotropia estrutural); e

b) mesmo no metatecto intensamente mobilizado (Foto 4 , amostra $H$ ) a petrofábrica indica que a gênese do material granítico ocorreu sob forte controle estrutural, durante o paroxismo metamórfico regional.

Os resultados gerais obtidos pela análise microtectônica dos migmatitos do "Grupo Amparo" sugerem a existência de apenas um ciclo global de deformação com a produção de tectonitos S, S-L, L-S e L parcialmente modificados por componentes lineares co-planares e elementos planares co-axiais. Tal fato não exclui, entretanto, a ocorrência de várias fases sucessivas de deformações homoaxiais ou mesmo que fases anteriores tenham sido obliteradas pelo último evento ora detectável pela análise microtectônica. 
Figura 8 - Estromatito, leucossoma, quartzo. Amostra A

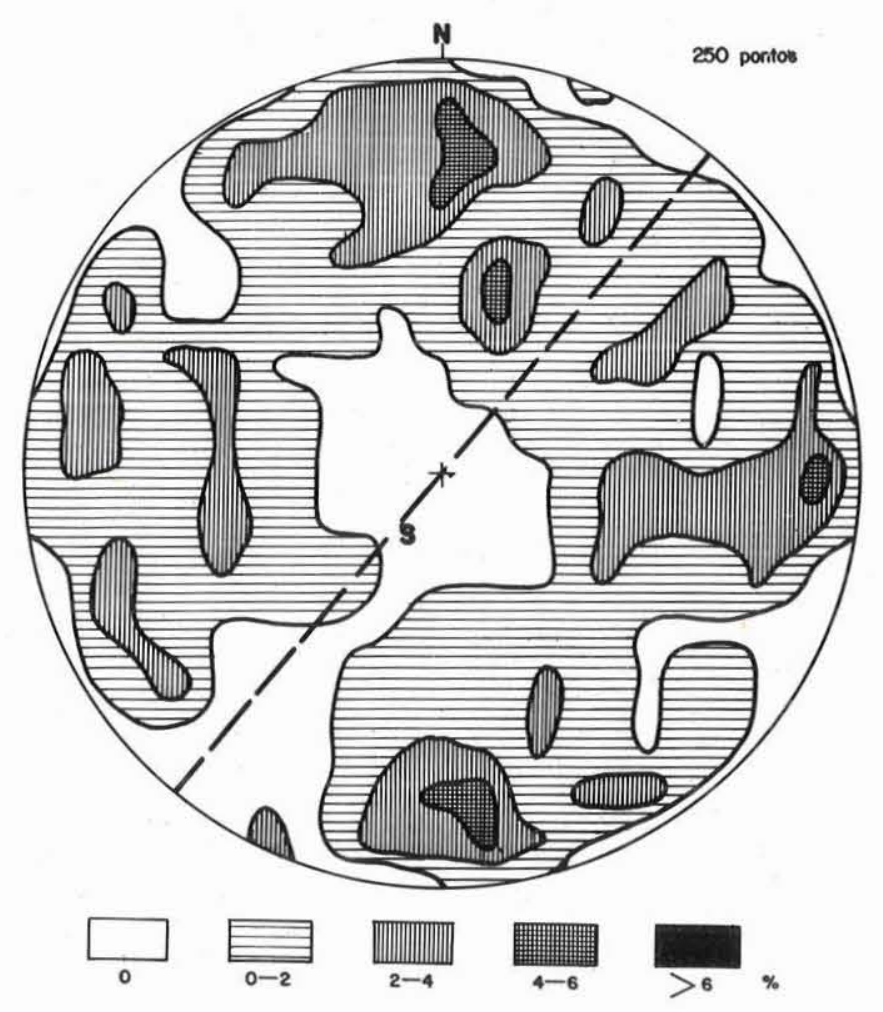

Figura 9 - Estromatito, leucossoma, quartzo. Amostra B

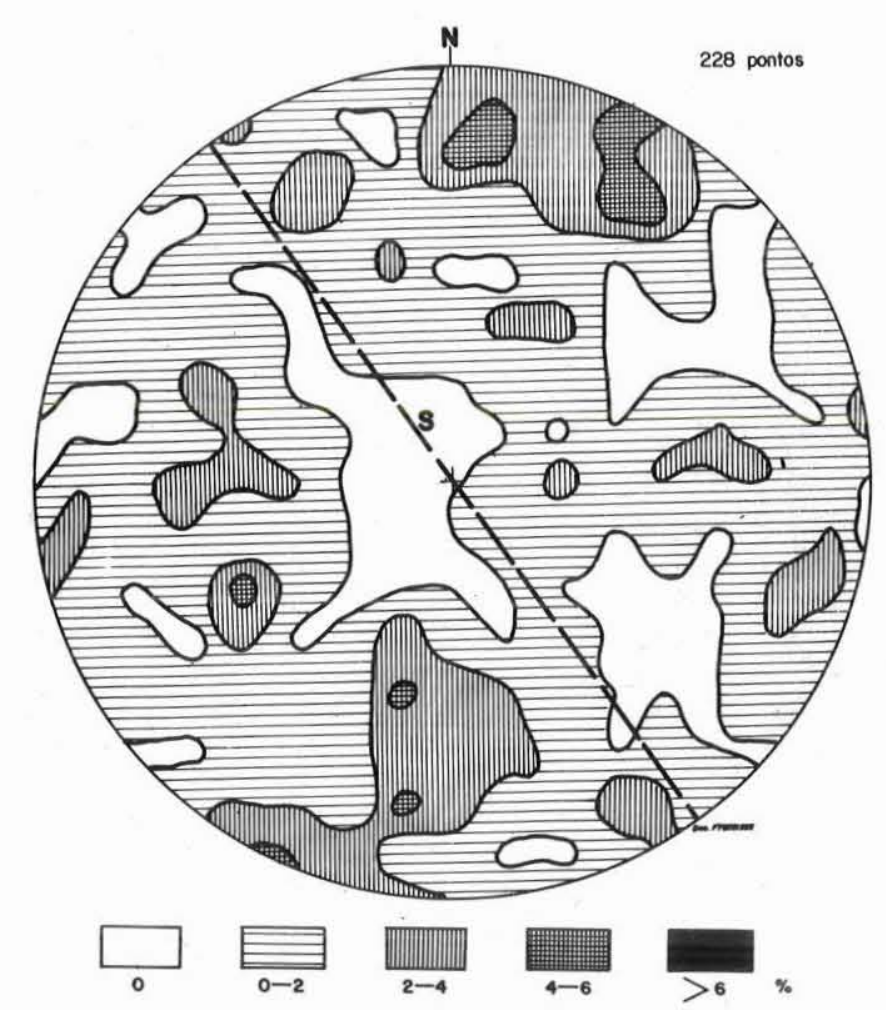



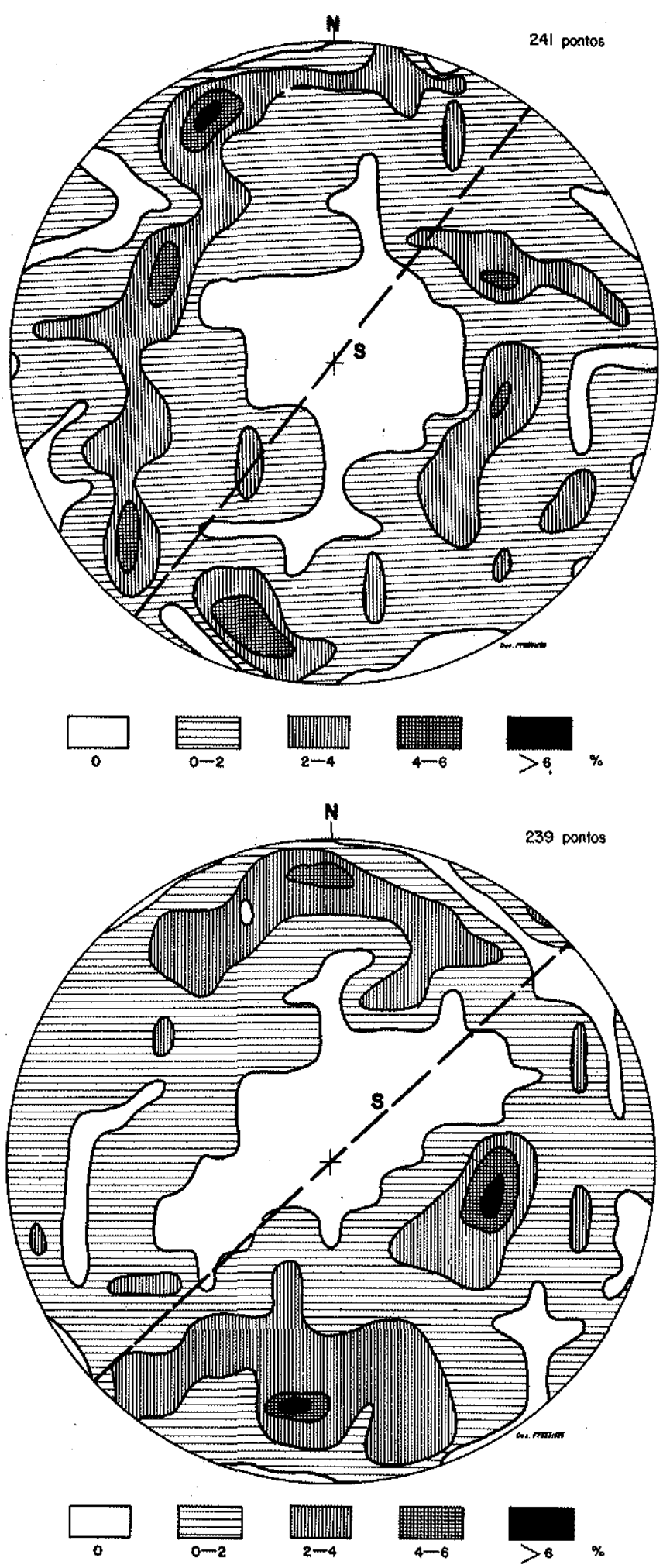

Figura 10 - Estromatito, leucossoma, quartzo. Amostra C
Figura 11 - Estromatito, leucossoma, quartzo. Amostra D 
Figura 12 - Estromatito, leucossoma, quartzo. Amostra $\mathbf{E}$

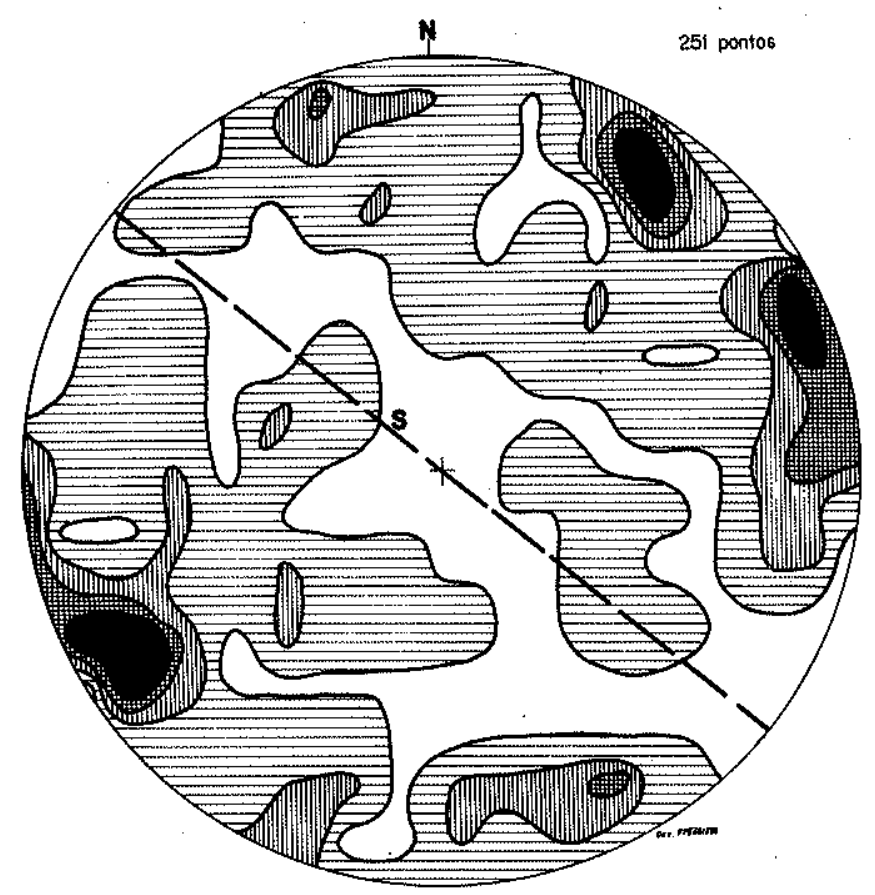

Figura 13 - Estromatito, leucossoma, quartzo. Amostra $\mathrm{F}$
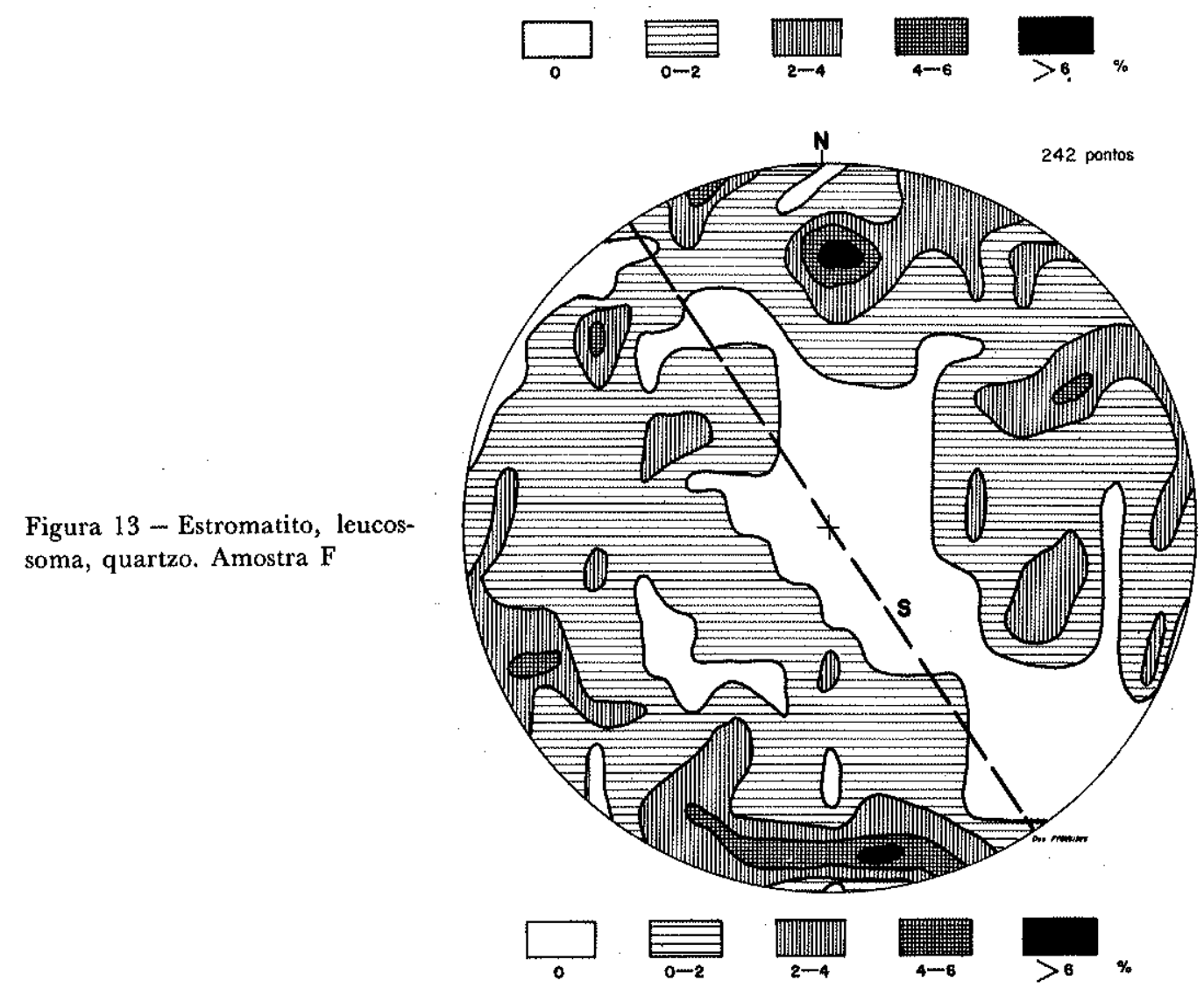


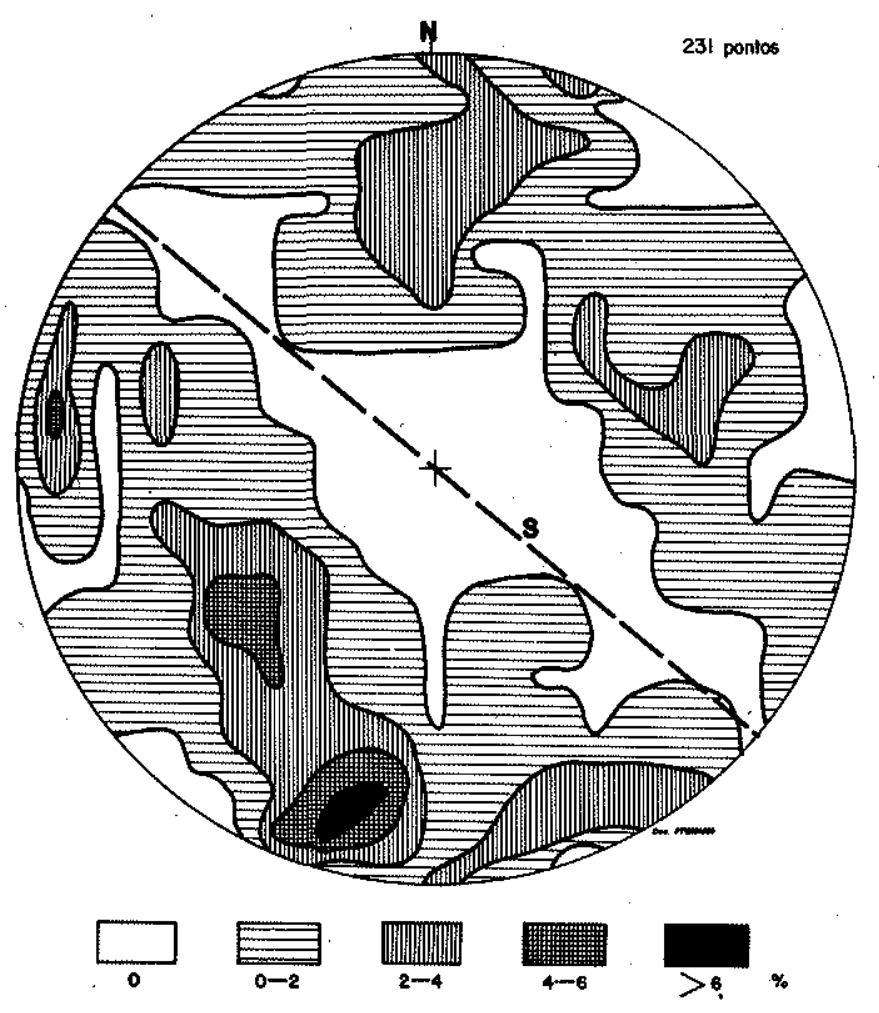

Figura 14 - Estromatito, leucossoma, quartzo. Amostra G

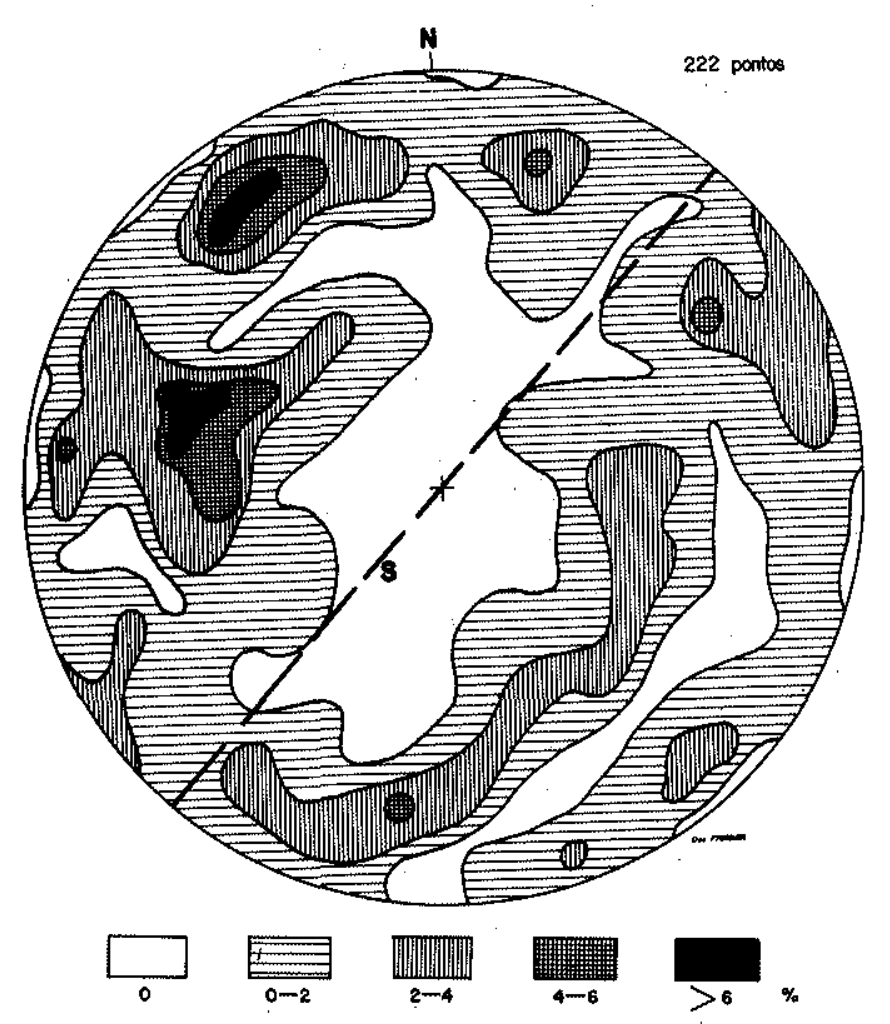

Figura 15 - Metatecto discordante, quartzo. Amostra $\mathrm{H}$ 
Agradecimentos $O s$ autores agradecem à Fundação de Amparo à Pesquisa do Estado de São Paulo pelo suporte dado ao presente trabalho pelo fornecimento de transporte para a realização dos trabalhos de campo.

\section{BIBLIOGRAFIA}

BONORINO, F. G. - 1970 - Migmatitos: bases para uma nomenclatura. Revista de la Associación Geológica Argentina, XXV (2): 262-273

BRAUN, G. - 1969 - Computer calculated counting nets for petrofabric and structural analysis. N. Jb. Miner. Mh., 10: $469-476$

CORDANI, V.G. e BITTENCOURT, I. - 1967 - Determinação de idade potássio-argônio em rochas do Grupo Açungui. S.B.G. Anais do XXI Congresso de Geologia, pp. 218-233

EBERT, H. - 1968 - Ocorrência da fáceis granulítica no Sul de Minas Gerais e em áreas adjacentes, em dependência da estrutura orogênica: hipóteses sobre sua origem. An. Acad. Bras. Ciên. 40 (Suplemento): 215-229

EBERT, H. e BROGHINI, M.F. - 1968 - Estudos estratigráficos e geocronológicos no Escudo Cristalino Brasileiro. Ciência e Cultura, 20 (3): 621-625

EBERT, H. - 1971 - Os Paraibides entre São João del Rei, Minas Gerais, e Itapira, São Paulo, e a bifurcação entre Paraibides e Araxaides, XXV Congresso Brasileiro de Geologia. Boletim Especial n. ${ }^{\circ} 1$, pp. 177-178

FLINN, D. - 1965 - On the symmetry principles and the deformation ellipsoid. Geol. Mag. 102 (1): $36-45$

FRANCO, R. R. e COUTINHO, J. M. V. - 1957 - Charnockitos e rochas associadas no município de Amparo e Socorro, Estado de São Paulo. An. Acad. Bras. Ciênc., 28 (3): 303-311

HASUI, Y., PENALVA, F, e HENNIES, W. T. - 1969 - Geologia do Grupo São Roque. Anais do XXIII Congr. Bras. Geol, pp. 101-134

HASUI, Y. e HAMA, M. - 1972 - Geocronologia do Grupo São Roque pelo método potássio-argónio. Rev. Bras. Geociências, 2 (1): 18-24

OliveirA, M. A. F. de - 1972 - Geologia e Petrologia da Regiăo de São José do Rio Pardo, Estado de São Paulo. Tese de doutoramento, Inst. Geociências, USP, 127 pp., inédito

WERNICK, E. - 1967 - A geologia da região de Amparo (leste do Estado de São Paulo). Tese de doutoramento, F.F.C.L., Rio Glaro, 225 pp., inédito

WERNICK, E. - 1972a - Sobre a ocorrencia de rochas calco-silicáticas nas proximidades de Duas Pontes, Município de Arcadas, Leste do Estado de São Paulo, Ciênc. Cult. 24 (4): 358-367

WERNICK, E. - 1972b - A geologia do Maciço Granítico de Morungaba, Leste do Estado de São Paulo, Escola de Engenharia de São Carlos, Boletim Geologia n. ${ }^{\circ} 16,110 \mathrm{pp}$.

WERNICK, E. - 1972c - Granitos porfiros dos arredores de Serra Negra, Valinhos e Amparo e suas relaçóes com o Maciço de Morungaba, Leste do Estado de Såo Paulo, Rev. Bras. Geociências 2(2): $129-138$

WERNICK, E. e PENALVA, F. - 1973 - Feiçסes estruturais de migmatitos ao norte e sul da falha de Jacutinga, Leste do Estado de São Paulo. Ciência e Cultura, Suplemento, 25 (6): 183 